\title{
Genome sequence of a VP2/NS junction region of pillar cell necrosis virus (PCNV) in cultured Japanese eel Anguilla japonica
}

\author{
Nam-Sil Lee ${ }^{1, *}$, Masato Miyata $^{2}$, Teruo Miyazaki ${ }^{2}$ \\ ${ }^{1}$ Department of Aquatic Life Medicine, Pukyong National University, 599-1 Daeyon-3 dong, Nam-gu, Pusan 608-737, Korea \\ ${ }^{2}$ Faculty of Bioresources, Mie University, 1515 Kamihama, Tsu, Mie 514-8507, Japan
}

\begin{abstract}
Pillar cell necrosis virus (PCNV) is an aquatic birnavirus that was isolated from farmed Japanese eel experiencing mass mortality. In this study, a VP2/NS junction region in genome segment A of PCNV was amplified by reverse transcriptase polymerase chain reaction (RT-PCR) and sequenced. The VP2/NS region in PCNV had the highest homology with that of a strain Ab of infectious pancreatic necrosis virus (IPNV). This result revealed that PCNV belongs to birnavirus genogroup II.
\end{abstract}

KEY WORDS: Genome sequence $\cdot$ VP2/NS junction region $\cdot$ Pillar cell necrosis virus $\cdot$ Birnavirus genogroup II

\section{INTRODUCTION}

In addition to infectious pancreatic necrosis virus (IPNV), many aquatic birnaviruses have been isolated from birds, insects, mollusks and teleosts, and have been reported to have many serotypes (Wolf et al. 1960, Cheville 1967, Dobost et al. 1979, Hill \& Way 1988, Wolf 1988, Heppell et al. 1992).

Birnaviruses contain 2 segments of double-stranded RNA (dsRNA). Genome segment A (approximately $3100 \mathrm{bp}$ ) encodes 3 polypeptides (VP2, NS, and VP3) in the order 5'-VP2-NS-VP3-3' (Nagy et al. 1987), and genome segment B (approximately 2900 bp) encodes VP1 only (Morgan et al. 1988). The junction region from VP2 to NS (VP2/NS) in genome segment A, having a length $310 \mathrm{bp}$, is a highly variable region that can be used to distinguish different strains. Heppell et al. (1993) compared the nucleotide sequence of 17 IPNVs, such as VR-299, Sp, Ab, N1, and He etc., and found

\footnotetext{
*E-mail: namsill@yahoo.co.kr
}

3 major groups, refered to as genogroups I, II, and III. Moreover, a genogroup of marine birnaviruses (MABV) was presented by Hosono et al. (1996), and a similar strain has recently been reported in Korea (Joh \& Heo 1999). However, it is known that there are some discrepancies between the results of the serological assay and those of the nucleotide sequencing. Furthermore, $\mathrm{Sp}$ and $\mathrm{Ab}$ were classified in different serotypes in the serological assay (Hill \& Way 1988), while results of the VP2/NS sequence revealed that both strains Sp and Ab should be in genogroup II (Heppell et al. 1993).

Pillar cell necrosis virus (PCNV) is a birnavirus that has been causing mass mortality in farmed Japanese eel Anguilla japonica. We reported that, serologically, PCNV is most similar to the strain Sp (Lee et al. 1999). In the present study, we compared the nucleotide sequence of the VP2/NS region of PCNV with the corresponding sequences of several other birnaviruses. These included IPNV isolates, strains VR-299, Sp, Ab, $\mathrm{He}$ and N1, and $1 \mathrm{MABV}$, strain SY. These regions were amplified by reverse transcriptase polymerase chain reaction (RT-PCR) and then sequenced. 


\section{MATERIAL AND METHODS}

Virus purification and viral dsRNA extraction. PCNV was propagated in EK-1 cells in L-15 with $2 \%$ fetal bovine serum (FBS) at $25^{\circ} \mathrm{C}$. When about $90 \%$ of the cells in the cell layer showed cytopathic effects, usually on about Day 5 post inoculation with PCNV, the cells were scraped off and centrifuged at $2000 \times g$. Subsequently, a 0.6 volume of $20 \%$ polyethylene glycol (PEG-6000) and $4.0 \mathrm{M} \mathrm{NaCl}$ were added, resulting in a final $\mathrm{NaCl}$ concentration of $2.5 \mathrm{M}$ solution, and the mixture was chilled on ice overnight. After centrifugation $\left(15000 \times g, 10 \mathrm{~min}\right.$, at $\left.4^{\circ} \mathrm{C}\right)$, the obtained pellet was suspended in Proteinase K lysis buffer (500 mM Tris-
$\mathrm{HCl}_{1} 100 \mathrm{mM}$ EDTA, $20 \%$ [w/v] SDS $1 \mathrm{mg} \mathrm{ml}^{-1}$ Proteinase $\mathrm{K}$ ). After lysis at $55^{\circ} \mathrm{C}$ for $2 \mathrm{~h}$, nucleic acid was extracted with phenol/chloroform treatment, and precipitated with a 0.1 volume of $3 \mathrm{M}$ sodium acetate and a 2.5 volume of ethanol. The dsRNA was resuspended in diethylpyrocarbonate (DEPC)-treated (RNase-free) water. The purity and concentration of the dsRNA was measured by a spectrophotometer (Amersham Pharmacia Biotec, USA) before it was stored at $-80^{\circ} \mathrm{C}$.

RT-PCR, cloning and sequencing. RT-PCR of the VP2/NS region in PCNV was performed using the forward primer (5'-AGAGATCACTGACTTCACAAGTGA-3') and the reverse primer (5'-TGTGCACCACAGGAAAGATGACTC-3') corresponding to IPNV Jasper

\begin{tabular}{l} 
PCNV-(eel) \\
\hline IPNV-(Ab) \\
IPNV-(Sp) \\
IPNV-(NI) \\
IPNV-(VR-299) \\
IPNV-(He) \\
MABV-(SY) \\
\\
PCNV-(eel) \\
IPNV-(Ab) \\
IPNV-(Sp) \\
IPNV-(NI) \\
IPNV-(VR-299) \\
IPNV-(He) \\
MABV-(SY) \\
PCNV-(eeI) \\
IPNV-(Ab) \\
IPNV-(Sp) \\
IPNV-(NI) \\
IPNV-(VR-299) \\
IPNV-(He) \\
MABV-(SY)
\end{tabular}

$\underline{P C N V}-($ ee 1$)$ IPNV-(Ab) IPNV-(Sp) I P N V- (N1) I P N V - ( VR-299)

I P NV- ( $\mathrm{He})$ $\mathrm{MABV}-(\mathrm{SY})$

$\underline{P C N V}-(\mathrm{eel})$ $\mathrm{IPNV}-(\mathrm{Ab})$ IPNV-(Sp) I P NV- ( N 1$)$ I P N V - (VR-299) I P NV- ( $\mathrm{He})$ $M A B V-(S Y)$

$\underline{P C N V}-($ eel) IPNV-(Ab) IPNV-( Sp) I P N V- ( N 1$)$ I P N V - ( VR-299) I P N - ( $\mathrm{He})$ $\mathrm{MABV}-(\mathrm{SY})$

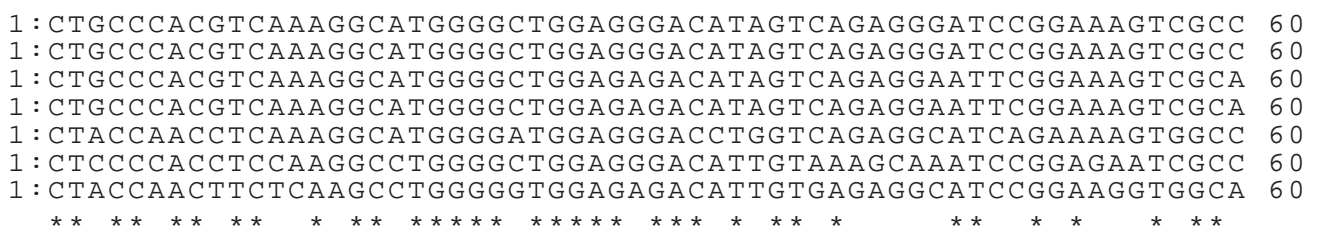

61: GCCCCAGTACTGTCAACGCTGTT TCCGATGGCAGCACCACTCATTGGGGTGGCAGACCAA 120 61: GCCCCAGTACTGTCAACGCTGTT TCCGATGGCAGCACCACTCATTGGAGTGGCAGACCAA 120 61: GCTCCTGTACTGTCAACGCTGTTTCCAATGGCAGCACCACTCATAGGAACGGCAGACCAA 120 61: GCTCCTGTACTGTCCACGCTGTTTCCAATGGCAGCACCACTCATAGGAATGGCAGACCAA 120 61: GCCCCCGTGCTGTCAACGCTCT TCCCAATGGCGGCTCCCCTTATAGGAGCTGCCGACCAA 120 61: GCTCCTGTGCTATCAACAATGTTCCCCATGGCCGCCCCTCTCATTGGAATGGCCGACCAG 120 61: GCACCAGTGCTGTCAACACTCTTCCCCATGGCAGCACCACTCATCGGAGCCGCCGACCAA 120

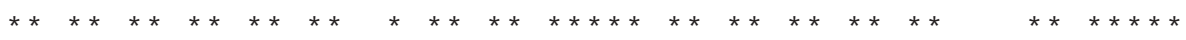

121: C TCA TCGGAGA TC TCACCAACACCAACGCA GCAGGCGGAAGG TACCGCTCCA TGGCCGCA 180 121 : CTCATCGGAGATCTCACCAACACCAACGCAGCAGGCGGAAGGTACCGCTCCATGGCCGCA 180 121 : T TCATTGGAGA TCTCACCAAGACCAACGCAGCAGGCGGAAGGTACCACTCCATGGCCGCA 180 121 : T TCATTGGAGATCTCACCAAGACCAACGCAGCAGGCGGAAGGTACCACTCCATGGCCGCA 180 121 : T TCAT TGGGGACCTCACCAAGACCAACTCAGCCGGGGGACGCTACCTGTCACACGCAGCC 180 121 : T TCATAGGCGACCTCACAAAAACCAACGCATCAGGCGGAAGATACAACTCACATGCCGCT 180 121 : T TCATCGGAGACCTGACCAAGACCAACGCAGCCGGAGGCCGCTACCTAACACATGCAGCA 180

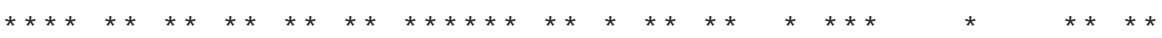

181: GGAGGACGCTACAAAGACGTAAGGACTCCTGGGCCAGCGGCGGACCCGACGGGAAGT TC 240 181 : GGAGGACGCTACAAGGATG TAA T G GAC T C C T GGGCCA GCGGCGGACCCGACGGGAAGT T 240 181: GGAGGGCGCCACAAAGACGTGCTCGAGTCCTGGGCAAGCGGAGGGCCCGACGGAAAAT TC 240 181 : GGAGGGCGCCACAAAGACGTGCTCGAGTCCTGGGCAAGCGGAGGGCCCGACGGAAAAT C 240 181 : GGAGGCCGCTACCATGATGTCATGGACTCATGGGCCAGCGGGTCCGAGGCAGGAAGCTAT 240 181 : GGAGGGCGGTACAAGGACGTTCTGGAGACATGGGCAAGCGGATCCAACACTGGCCGCT TC 240 18 : GGAGGACGCTACACTGATGTAATGGACTCCTGGGCCAGCGGCACAGACACTGGGAGGTTC 240

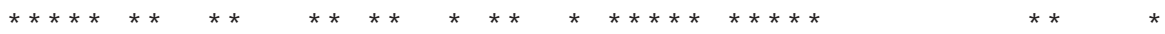

241: TCCCAGGCTCTAAAGAACAGACTGGAGTCTGCCAACTACGAGGAAGTCGAGCTTCCTCCC 300 241 : TCCCAGGCTCTAAAGAACAGACTGGAGTCTGCCAACTACGAGGAAGTCGAGCTTCCTCCC 300 241: TCCCGAGCCCTCAAGAACAGGCTGGAG T C CGCGAACTACGAGGAAGTCGAGCT TCCACCC 300 241 : TCCCGAGCCCTCAAGAACAGGCTGGAGTCCGCCAACTACGAGGAAGTCGAGCTTCCACCC 300 241 : TCAAAGCACCTCAAGACCCGGCTTGAGTCCAATAACTATGAGGAAGTGGAGCTTCCAAAG 300 241 : TCAATGAGCCTCAAGAAACGCCTAGAGTCAACAAACTATGAGGAAGTGGAACTTCCACGC 300 241 : TCACGCAACCTCAAAGACCGGCTGGAGTCAAACAACTATGAGGAGATGGAACTTCCTCCA 300



$301:$ C TTCAAAAG

301 : С СТ TAAAAG

301 : $C$ C $\mathrm{T} C A A A A G$

301 : $C$ C $\mathrm{TCAAAAG}$

$301: C C A A C A A A G G$

301 : $C$ C CGAACGTG

301 : CCAACGAAAG

$$
\star \star
$$

Fig. 1. Nucleotide sequence alignment of VP2/NS region in PCNV and other birnaviridae. All the sequences were displayed from the $5^{\prime}$ to $3^{\prime}$ direction. The conserved nucleotides in all the sequences are indicated by an asterisk ( $\star$ ). The different nucleotides between PCNV and IPNV-Ab are boxed 
segment A according to Heppell et al. (1992). The obtained RT-PCR product was connected with the pGEM-T vector (Promega, USA) following the supplier's recommendations. The recombinant plasmid was transformed into Escherichia coli strain XLI-Blue $\mathrm{MRF}^{\prime}$ (Stratagene, USA) using the calcium chloride method (Sambrook et al. 1989), and recombinant clones were extracted using the alkali-sodium dodecyl sulfate (alkali-SDS) method (Sambrook et al. 1989). Nucleotide sequences were determined with the thermo sequences fluorescent-labeled primer cycle sequencing kit (Amersham Pharmacia Biotec, USA) with a DNA sequencer DNA-4000L (Li-Cor, USA).

\section{RESULTS}

An approximately $0.3 \mathrm{~kb}$ long RT-PCR product was obtained. As this was the expected length of the VP2/NS region, it was inserted in the plasmid vector and the recombinant plasmid was used to transform Escherichia coli cells. Three clones that contained the RT-PCR product were sequenced. The nucleotide sequences were determined for both the sense and antisense strands. The sequences of all 3 distinct clones were identical. The obtained sequence was homologous to the previously reported sequences of the VP2/NS regions of the major IPNVs (strains Ab, $\mathrm{Sp}, \mathrm{He}, \mathrm{VR}-299, \mathrm{~N} 1$ ) and MABV (strain SY) (GenBank accession codes are IPNLWVR, IPNSEGAA, IPNSPAA, IPNSEGA, IPNHEAA and BIVVP2NS2, respectively). The sequence of the VP2/NS region in PCNV was highly homologous with strains Ab (99.0\%), N1 $(89.0 \%)$ and $\mathrm{Sp}(88.7 \%)$ (Fig. 1, Table 1), but less homologous with strains VR-299 (74.3\%), He (72.2\%) and SY $(75.2 \%)$. The phylogenetic tree was constructed based on the predicted amino acids sequence alignment of the VP2/NS region in PCNV and other birnaviruses (data not shown). PCNV was in the same branch as strains $\mathrm{Sp}, \mathrm{Ab}$, and N1 (genogroup II). The PCNV branch was different from the branches of strain VR299 (genogroup I) and He (genogroup III) of IPNV as well as from the strain SY of MABV (Fig. 2).

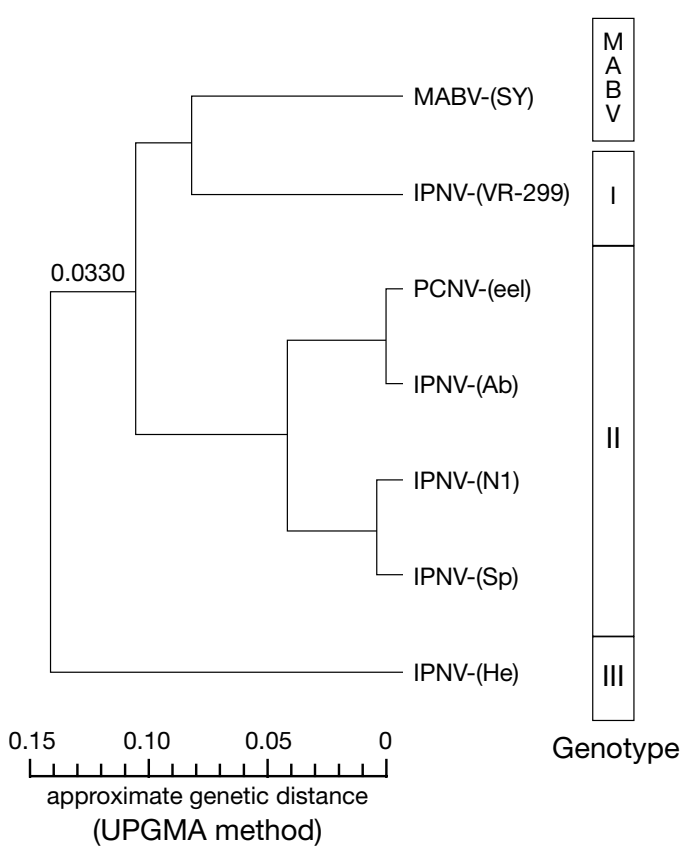

Fig 2. Phylogenetic tree (UPGMA) represents the relationship between the PCNV and the other birnaviruses. Horizontal bar indicates the genetic distance. Genogroups proposed by Heppell et al. (1993) and Hosono et al. (1996)

\section{DISCUSSION}

In this study, we determined the nucleotide sequence of the reverse-transcribed VP2/NS region in PCNV. Current evidence indicates that VP2 of birnaviruses carries the serotype-specific epitopes that are responsible for the induction of neutralizing protective antibodies. The conformation of these epitopes is highly dependent on the sequence of this region (Heppell et al. 1995). Heppell et al. (1993) established a PCR assay to amplify and characterize the highly variable VP2/NS junction region. This region could be prepared easily, and more than 20 sequences were deposited in the genome database for the genogrouping of aquatic birnaviruses. Therefore, this region was characterized in the present study.

Table 1. Homologies between nucleotide sequences deduced from the cDNA fragment of PCNV and the corresponding portion on 6 published sequences of aquatic birnaviruses (at the $310 \mathrm{bp}$ of the VP2/NS junction region) (similarities, in \%)

\begin{tabular}{|c|c|c|c|c|c|c|}
\hline IPNV-(Ab) & 99.0 & & & & & \\
\hline IPNV-(He) & 72.2 & 72.5 & & & & \\
\hline IPNV-(N1) & 89.0 & 88.7 & 74.6 & & & \\
\hline IPNV-(Sp) & 88.7 & 88.4 & 74.6 & 99.0 & & \\
\hline IPNV-(VR-299) & 74.3 & 74.9 & 72.5 & 73.6 & 74.3 & \\
\hline MABV-(SY) & 75.2 & 75.8 & 72.5 & 72.6 & 72.9 & 78.1 \\
\hline Strain & PCNV-(eel) & IPNV-(Ab) & IPNV-(He) & IPNV-(N1) & IPNV-(Sp) & IPNV-(VR-299) \\
\hline
\end{tabular}


An amplified RT-PCR product of PCNV had exactly the expected length: $310 \mathrm{bp}$. The sequence homology values among previously known IPNVs, MABV and PCNV ranged from 99.0 to $72.2 \%$ as shown in Table 1. PCNV was most homologous with strain Ab (99.0\%), although it was serologically closer to Sp than Ab (Lee et al. 1999). A similar state was found in the strain N1, which was recognized as a new serotype in 1988 (Christie et al. 1988). However, the VP2/NS regions of strains N1 and Sp differed by only 3 bases (Havarstein et al. 1990). Furthermore, some birnaviruses that were reported to belong to different serotypes were found to be closely related to each other at the genetic level and were categorized into 3 genogroups (Heppell et al. 1993).

The nucleotide sequence of the reverse-transcribed VP2/NS region determined in this study indicates that the PCNV belongs to genogroup II of Heppell et al. (1993) and Hosono et al. (1996), which includes both strains $\mathrm{Sp}$ and $\mathrm{Ab}$.

\section{LITERATURE CITED}

Cheville NF (1967) Studies on the pathogenesis of Gumboro disease in the bursa of Fabricus, spleen and thymus of the chicken. Am J Pathol 51:527-551

Christie KE, Havarstein LS, Djupvik HO, Ness S, Endresen C (1988) Characterization of a new serotype on infectious pancreatic necrosis virus isolated from Atlantic salmon. Arch Virol 103:167-177

Dobos P, Hill BJ, Hallett R, Kells DTC, Becht H, Tenings D (1979) Biophysical and biochemical characterization of five animal viruses with bisegmented double-stranded RNA genomes. J Virol 32:593-605

Havarstein LS, Kalland KH, Christie KE, Endresen C (1990) Sequence of the large double-stranded RNA segment of the N1 strain of infectious pancreatic necrosis virus: a comparison with other Birnaviridae. J Gen Virol 71: 299-308

Editorial responsibility: Jo-Ann Leong,

Corvallis, Oregon, USA
Heppell J, Berthiaume L, Tarrab E, Lecomte J, Arella M (1992) Evidence of genomic variations between infectious pancreatic necrosis virus strains determined by restriction fragment profiles. J Gen Virol 73:2863-2870

Heppell J, Berthiaume L, Corbin F, Tarrab E, Lecomte J, Arella M (1993) Comparison of amino acid sequences deduced from a cDNA fragment obtained from infectious pancreatic necrosis virus (IPNV) strains of different serotypes. Virology 195:840-844

Heppell J, Tarrab E, Lecomte J, Berthiaume L, Arella M (1995) Strain variability and localization of important epitopes on the major structural protein (VP2) of infectious pancreatic necrosis virus. Virology 214:40-49

Hill BJ, Way K (1988) Proposed standardization of the serological classification of aquatic birnaviruses. In: Conference handbook, Abstract. International Fish Health Conference, Vancouver, p 151

Hosono N, Suzuki S, Kusuda R (1996) Genogrouping of birnaviruses isolate from marine fish: a comparison of VP/NS junction regions on genome segment A. J Fish Dis 19: 295-302

Joh SJ, Heo GJ (1999) Genetic analysis of the VP2/NS junction region on segment A of marine birnavirus isolated from rockfish (Sebastes schlegeli) cultured in Korea. Bull Eur Assoc Fish Pathol 19:190-195

Lee NS, Nomura Y, Miyazaki T (1999) Gill lamellar pillar cell necrosis: a new birnaviral gill disease in cultured Japanese eels. Dis Aquat Org 37:13-20

Morgan MM, Macreadie IG, Harley VR, Hudson PJ, Azard AA (1988) Sequence of the small double-stranded RNA genomic segment of infectious bursal disease virus and its deduced $90 \mathrm{kDa}$ product. Virology 163:240-242

Nagy E, Duncan R, Krell P, Dobos P (1987) Mapping of the large RNA genome segment of infectious pancreatic necrosis virus by hybrid arrested translation. Virology 158: 211-217

Sambrook J, Fritsch E, Maniatis T (1989) Molecular cloning. A laboratory manual, 2nd edn. Cold Spring Harbor Laboratory Press, NY

Wolf K (1988) Fish viruses and fish viral diseases. Cornell University Press, Ithaca

Wolf K, Snjeszko SF, Dunbar CE, Pyle E (1960) Virus nature of infectious pancreatic necrosis in trout. Soc Exp Biol Med Proc 104:105-108

Submitted: June 15, 2000; Accepted: December 28, 2000

Proofs received from author(s): April 3, 2001 